\title{
Preliminary Evaluation of Probiotic Properties of Lactobacillus Strains Isolated from Sardinian Dairy Products
}

\author{
Maria Barbara Pisano, ${ }^{1}$ Silvia Viale, ${ }^{1}$ Stefania Conti, ${ }^{1}$ Maria Elisabetta Fadda, ${ }^{1}$ \\ Maura Deplano, ${ }^{1}$ Maria Paola Melis, ${ }^{2}$ Monica Deiana, ${ }^{2}$ and Sofia Cosentino ${ }^{1}$ \\ ${ }^{1}$ Department of Public Health, Clinical and Molecular Medicine, University of Cagliari, Cittadella Universitaria, \\ S.S. 554, Km 4,5, 09042 Monserrato, Italy \\ ${ }^{2}$ Department of Biomedical Sciences, Unit of Experimental Pathology, University of Cagliari, Cittadella Universitaria, \\ S.S. 554, Km 4,5, 09042 Monserrato, Italy
}

Correspondence should be addressed to Sofia Cosentino; scosenti@unica.it

Received 25 February 2014; Revised 29 May 2014; Accepted 11 June 2014; Published 26 June 2014

Academic Editor: Himanshu Garg

Copyright (C) 2014 Maria Barbara Pisano et al. This is an open access article distributed under the Creative Commons Attribution License, which permits unrestricted use, distribution, and reproduction in any medium, provided the original work is properly cited.

Twenty-three Lactobacillus strains of dairy origin were evaluated for some functional properties relevant to their use as probiotics. A preliminary subtractive screening based on the abilities to inhibit the growth of microbial pathogens and hydrolyze conjugated bile salts was applied, and six strains were selected for further characterization including survival under gastrointestinal environmental conditions, adhesion to gut epithelial tissue, enzymatic activity, and some safety properties. All selected strains maintained elevated cell numbers under conditions simulating passage through the human gastrointestinal tract, well comparable to the values obtained for the probiotic strain Lactobacillus rhamnosus GG, and were able to adhere to Caco-2 cells to various extents (from 3 to $20 \%$ ). All strains exhibited high aminopeptidase, and absent or very low proteolytic and strong $\beta$-galactosidase activities; none was found to be haemolytic or to produce biogenic amines and all were susceptible to tetracycline, chloramphenicol, erythromycin, ampicillin, and amoxicillin/clavulanic acid. Our results indicate that the Lactobacillus strains analyzed could be considered appropriate probiotic candidates, due to resistance to GIT simulated conditions, antimicrobial activity, adhesion to Caco-2 cell-line, and absence of undesirable properties. They could be used as adjunct cultures for contributing to the quality and health related functional properties of dairy products.

\section{Introduction}

Lactic acid bacteria (LAB) are widespread in nature and are one of the major microbial groups involved in the fermentation of different types of food. They represent the dominant microorganisms in milk and milk products where they play important roles during both manufacture and ripening. $\mathrm{LAB}$ possess a large number of metabolic properties that are responsible for the organoleptic characteristics of the final product as well as its preservation and microbial safety [1]. They are also known for their potential health and nutritional benefits and therefore are considered "probiotics" or "live microorganisms which upon ingestion in adequate amounts confer health benefits to the host" [2].
As a result of increasing awareness of the close interrelationship between health and diet, special attention is presently given to functional properties of LAB associated with traditional fermented products. These foods could represent alternative sources of novel probiotic candidates with physiological and functional properties for potential biotechnological use in the manufacturing of functional products in which the probiotic cultures are more active and protected from the gastrointestinal stress.

Among food ecosystem, cheese has some intrinsic chemical and physical characteristics (high $\mathrm{pH}$, buffering capacity, solid consistency, high fat content, and high nutrient availability) that make it suitable for delivery of viable probiotic microorganisms into the human intestine [3]. Raw 
milk and traditional cheeses are rich environments with a varied and complex autochthonous microbiota composed of diverse group of microorganisms, including LAB, which contribute to the biopreservation and the development of organoleptic properties of the final product. LAB may play different roles in cheese-making; some species designated as starter LAB (SLAB) participate in the fermentation process, whereas some others indicated as nonstarter LAB (NSLAB) are implicated in the maturation process [4].

Among LAB, Lactobacillus strains have been extensively exploited for their probiotic properties [5] and are applied as adjunct cultures in various types of food products [6].

Lactobacilli are generally regarded as safe (GRAS) due to their long history of safe use and their presence in the intestinal microbiota of humans, and several species have received the qualified presumption of safety (QPS) status $[7,8]$.

Recently an increasing interest was paid to the possibility that strains belonging to species such as Lactobacillus plantarum, L. paracasei, and L. brevis, which constitute the majority of NSLAB found in most ripened cheese varieties, may play a role as health promoters, beyond their technological function [9].

To perform their probiotic action these bacteria must arrive at the intestinal tract alive. This requires their survival during food processing, product maturation, and shelflife and, after consumption, their resistance to the acidic conditions of the stomach as well as to bile salts in the small intestine [10].

As a part of a larger study involving the selection and characterization of new probiotic candidates, 23 autochthonous Lactobacillus strains of dairy origin were investigated for some functional properties relevant to their use as probiotic cultures. Antagonism toward microbial pathogens, ability to deconjugate bile salts, survival in the gastrointestinal tract, adhesion capability to intestinal epithelial cells, enzymatic activities, and some safety features such as hemolytic activity, antimicrobial resistance, and production of biogenic amines were in vitro analyzed.

\section{Materials and Methods}

2.1. Bacterial Strains and Growth Conditions. A total of 23 Lactobacillus strains (10 L. paracasei, 9 L. plantarum, and 4 L. brevis) isolated from raw milk and artisanal ewes' cheeses were included in this study. The strains were identified on the basis of phenotypic tests and genetic analysis based on polymerase chain reaction amplification using species-specific primers derived from 16S rRNA sequences, as previously reported [11]. The strains were maintained at $-20^{\circ} \mathrm{C}$ in MRS broth (Microbiol, Cagliari, Italy) with $15 \%$ (v/v) glycerol and propagated three times in MRS broth for activation prior to experimental use. Listeria monocytogenes ATCC 7644, Escherichia coli ATCC 35150, Enterococcus faecalis ATCC 29212, Salmonella Typhimurium ATCC 14028, Staphylococcus aureus ATCC 25923, and Candida albicans ATCC 10231 were used as indicators. All indicator strains were stored on nutrient broth (Microbiol) plus 20\% (v/v) glycerol at $-20^{\circ} \mathrm{C}$. Before use, they were subcultured twice in appropriate medium.

2.2. Antimicrobial Activity. The strains were screened for antimicrobial compounds production against the indicator strains using an agar spot method [12]. Overnight cultures of Lactobacilli were spotted onto the surface of MRS agar $(1.2 \%$ $(\mathrm{w} / \mathrm{v})$ agar- $0.2 \%(\mathrm{w} / \mathrm{v})$ glucose) plates, which were then incubated anaerobically for $24 \mathrm{~h}$ at $37^{\circ} \mathrm{C}$. The indicator strains were inoculated into $7 \mathrm{~mL}$ of soft agar medium (nutrient broth containing $0.7 \% \mathrm{w} / \mathrm{v}$ agar) to a final concentration of approximately $10^{7}$ colony forming unit (cfu)/mL; then the soft media were poured on the plates. After $24 \mathrm{~h}$ of incubation at the optimal growth temperature and atmosphere for the indicator strains, inhibition halos were measured. The width of the clear zone $(R)$ was calculated as follows: $R=\left(d_{\text {Inhib }}-\right.$ $\left.d_{\text {Spot }}\right) / 2$, where $d_{\text {Inhib }}$ is the diameter of the zone without pathogen growth and $d_{\text {Spot }}$ is the diameter of the spot.

2.3. Bile Salt Hydrolase Activity. Bile salt hydrolase (BSH) activity was screened by spotting in duplicate $10 \mu \mathrm{L}$ of cultures grown overnight in MRS broth on the surface of MRS agar plates supplemented with $0.5 \%(\mathrm{w} / \mathrm{v})$ sodium salt taurodeoxycholic acid (TDCA, Sigma, Milano, Italy) or $0.2 \%$ (w/v) glycodeoxycholic acid (GDCA, Sigma) and $0.37 \mathrm{~g} / \mathrm{L}$ of $\mathrm{CaCl}_{2}$ [13]. Plates were incubated in anaerobic conditions at $37^{\circ} \mathrm{C}$ for $72 \mathrm{~h}$. The presence of halos around colonies (in MRSGDCA) or white opaque colonies (in MRS-TDCA) indicated $\mathrm{BSH}$ activity. MRS agar plates without supplementation were used as negative controls. Enterococcus faecalis ATCC 14433 was used as BSH-positive strain.

2.4. In Vitro Resistance to Gastrointestinal Conditions. Transit tolerance in the upper GIT was assessed using an in vitro model simulating gastric and pancreatic juices (simulated stomach-duodenum passage, SSDP), as reported by Vizoso Pinto et al. [14]. The strains were inoculated to a final concentration of approximately $2.5 \times 10^{8} \mathrm{cfu} / \mathrm{mL}$ in $10 \mathrm{~mL}$ of simulated gastric juice $(6.2 \mathrm{~g} / \mathrm{L} \mathrm{NaCl}, 2.2 \mathrm{~g} / \mathrm{L} \mathrm{KCl}, 0.22 \mathrm{~g} / \mathrm{L}$ $\mathrm{CaCl}_{2}, 1.2 \mathrm{~g} / \mathrm{L} \mathrm{NaHCO}_{3}, 0.3 \%$ pepsin, and $\left.\mathrm{pH} 3.0\right)$ and incubated at $37^{\circ} \mathrm{C}$ in a shaking water bath (Dubnoff 750, Asal, Milano, Italy) to simulate peristalsis. After $90 \mathrm{~min}, 17.5 \mathrm{~mL}$ of synthetic duodenum juice $\left(6.4 \mathrm{~g} / \mathrm{L} \mathrm{NaHCO}_{3}, 0.239 \mathrm{~g} / \mathrm{L} \mathrm{KCl}\right.$, $1.28 \mathrm{~g} / \mathrm{L} \mathrm{NaCl}$, and $0.1 \%$ pancreatin), adjusted to $\mathrm{pH} 7.4$ with $5 \mathrm{M} \mathrm{HCl}$, and $4 \mathrm{~mL}$ of $10 \%(\mathrm{w} / \mathrm{v})$ oxgall (Sigma) were added to the cell suspensions to simulate passage into the upper intestinal tract [15]. After 0,90 , and $180 \mathrm{~min}$ of incubation, the survival rate was determined by the plate method using MRS incubated anaerobically at $37^{\circ} \mathrm{C}$ for $48 \mathrm{~h}$. The experiments were repeated twice and results are expressed as the mean log $\mathrm{cfu} / \mathrm{mL}$.

2.5. Adhesion Properties to Human Cell Line. The human colonic carcinoma cell line Caco-2 (ECACC, Salisbury, UK) was routinely cultured in Dulbecco's modified Eagle's minimal essential medium DMEM (Sigma), supplemented with $10 \%(\mathrm{w} / \mathrm{v})$ foetal bovine serum (FBS, Sigma), 1\% (w/v) nonessential amino acids solution (Sigma), and antibiotic 
solution ( $100 \mathrm{U} / \mathrm{mL}$ penicillin, $100 \mu \mathrm{g} / \mathrm{mL}$ streptomycin). Cells were maintained in T-75 culture flasks at $37^{\circ} \mathrm{C}$ in a $5 \%$ $\mathrm{CO}_{2}$ atmosphere. For adhesion assay, the Caco- 2 cells were seeded at a concentration of $10^{5}$ cells/well in 6-well tissue culture plates (Falcon) to obtain confluence and cultured for 20 days prior to use in adhesion assay. The cell culture medium was changed on alternate days and replaced by fresh DMEM supplemented with $2 \%$ (w/v) FBS and without antibiotic at least $1 \mathrm{~h}$ before the adhesion assay. A $1 \mathrm{~mL}$ aliquot of Lactobacillus suspension $\left(10^{8} \mathrm{ufc} / \mathrm{mL}\right.$ in phosphate buffered saline, PBS) was added to each well of the tissue culture plate and incubated at $37^{\circ} \mathrm{C}$ in $5 \% \mathrm{CO}_{2}$ atmosphere for $3 \mathrm{~h}$. Afterwards, the cells were washed three times with $1 \mathrm{~mL}$ of PBS in order to remove nonadherent bacteria and lysed by addition of Triton X 100 ( $0.05 \%$ solution) for $10 \mathrm{~min}$; then appropriate dilutions were plated on MRS agar. Adhesion was expressed as the percentage of bacteria adhered to Caco-2 cells compared to the initial amount of bacteria.

2.6. Enzymatic Activities. Enzymatic activities of Lactobacillus strains were evaluated by using the API ZYM galleries (BioMérieux, Itay) as described by the manufacturer. The results were graded from 0 to 5 by comparing the colour developed within $5 \mathrm{~min}$ with the API-ZYM colour reaction chart. The results were expressed in nanomoles of hydrolysed substrate, from the intensity of the reactions obtained, in the range 0 (no activity) to 5 (40 or more nanomoles liberated), following the manufacturer's instructions.

2.7. Safety Assessment. The method of Bover-Cid and Holzapfel [16] was used to screen Lactobacillus strains for the production of biogenic amines. Briefly, the test strains were subcultured twice at $24 \mathrm{~h}$ intervals in MRS broth containing $1 \%$ of each precursor amino acid: tyrosine disodium salt, Lhistidine monohydrochloride, L-ornithine monohydrochloride, and lysine monohydrochloride (Sigma), and 0.005\% pyridoxal-5-phosphate (Sigma) as a codecarboxylase factor. All strains were then streaked in duplicate on decarboxylase medium plates each containing only one of the abovementioned amino acids and bromocresol purple as $\mathrm{pH}$ indicator and incubated for 4 days in anaerobic conditions at $37^{\circ} \mathrm{C}$. Decarboxylase medium without amino acids was used as control. A colour change from brown to purple in the medium indicated an increase in $\mathrm{pH}$ and was considered a positive result.

Antibiotic susceptibilitytesting was carried out by disc diffusion method according to the Clinical and Laboratory Standards Institute (CLSI) guidelines [17] but MuellerHinton agar was replaced by MRS agar (Microbiol). The following antibiotics (Oxoid or BBL) were tested: ampicillin (AM; $10 \mu \mathrm{g}$ ), amoxicillin/clavulanic acid (AmC; $30 \mu \mathrm{g})$, vancomycin (VA; $30 \mu \mathrm{g}$ ), teicoplanin (TEC; $30 \mu \mathrm{g}$ ) (inhibitors of cell wall synthesis), tetracycline (TE; $30 \mu \mathrm{g})$, streptomycin (S; $10 \mu \mathrm{g})$, kanamycin (K; $30 \mu \mathrm{g})$, gentamicin (GM; $10 \mu \mathrm{g})$, chloramphenicol $(\mathrm{C} ; 30 \mu \mathrm{g}$ ), erythromycin $(\mathrm{E} ; 15 \mu \mathrm{g}$ ) (inhibitors of protein synthesis), ciprofloxacin (CIP; $5 \mu \mathrm{g}$ ), and rifampicin (RA; $30 \mu \mathrm{g}$ ) (inhibitors of nucleic acids). A suspension from fresh overnight cultures with a density of McFarland 0.5 in buffered saline was plated on MRS agar plates; then antibiotic discs were dispensed onto the plates. After incubation at $37^{\circ} \mathrm{C}$ for $24 \mathrm{~h}$ in anaerobiosis, the diameters of the bacterial free-zone were measured and results expressed in terms of resistance according to the interpretative criteria issued by the CLSI [18].

Haemolytic activity was determined by streaking the strains on Columbia Blood (Microbiol) agar plates supplemented with $5 \%$ defibrinated sheep blood after $48 \mathrm{~h}$ of incubation at $37^{\circ} \mathrm{C}$. The haemolytic reaction was recorded by observation of a clear zone of hydrolysis around the colonies ( $\beta$-haemolysis), a partial hydrolysis and greenish zone $(\alpha$ haemolysis), or no reaction ( $\gamma$-haemolysis).

2.8. Statistical Analysis. Statistical analysis of data was carried out using GraphPad Prism Statistics software package version 3.00 (GraphPad Prism Software Inc., San Diego, CA, USA). One-way ANOVA followed by Bonferroni test was used to determine significant differences of viability of the Lactobacillus strains during SSDP treatment and with respect to the adhesion ability. Data were analysed at the significance level of $P<0.05$.

\section{Results and Discussion}

A preliminary subtractive screening based on the abilities to inhibit the growth of microbial pathogens and hydrolyse conjugated bile salts was applied to the strains. As shown in Table 1, most strains were able to inhibit the growth of L. monocytogenes, S. aureus, and E. coli O157:H7 with clear inhibition zones of more than $6 \mathrm{~mm}$ in agar-spot plates. A lower activity was detected against E. faecalis, while one strain showed an inhibition zone of $4 \mathrm{~mm}$ against $C$. albicans ATCC 10231. Such broad antagonistic activity of Lactobacillus towards different pathogens has been reported $[19,20]$; however, 27 strains of $L$. plantarum isolated from cheese showed no activity against selected indicator pathogens [21].

$\mathrm{LAB}$ are known to produce many different substances with antimicrobial activity, including the major metabolic end products such as organic acids, hydrogen peroxide, ethanol, and bacteriocins [22]. When the strains with the best inhibitory activity in the agar spot-test were further tested using the well-diffusion assay, to investigate the presence of bacteriocin-like compounds, no inhibitory activity was observed (data not shown), presumably indicating that the production of organic acids was responsible for the observed antimicrobial effect. The inhibitory effect of hydrogen peroxide was excluded due to incubation in anaerobic conditions.

$\mathrm{BSH}$ activity is a relevant property for probiotic strains to survive the toxicity of conjugated bile salts in the duodenum [23]. In our study, while all strains were able to grow in the presence of conjugated bile salts after $72 \mathrm{~h}$ of incubation, only five (L. plantarum 11/20966, 4/16868, 19/20711 and L. paracasei 62LP39, 1A6 M) demonstrated also the ability to hydrolyze both sodium glycodeoxycholate (GDCA) and sodium taurodeoxycholate (TDCA), and four were able to deconjugate only GDCA, as indicated by the BSH test on agar plates. Some authors have shown that in Lactobacilli 
TABLE 1: Antimicrobial activity against the microbial pathogens tested, bile salt hydrolase (BSH) activity, and raffinose fermentation of selected potential probiotic Lactobacillus strains isolated from Sardinian dairy products.

\begin{tabular}{|c|c|c|c|c|c|c|c|c|c|}
\hline \multirow{2}{*}{ Strains } & \multicolumn{6}{|c|}{ Target strains } & \multicolumn{3}{|c|}{ Hydrolysis of } \\
\hline & $\begin{array}{c}\text { S. aureus } \\
\text { ATCC } 25923\end{array}$ & $\begin{array}{c}\text { L. monocytogenes } \\
\text { ATCC } 7644\end{array}$ & $\begin{array}{c}\text { E. coli } \\
\text { ATCC } 35150\end{array}$ & $\begin{array}{l}\text { E. faecalis } \\
\text { ATCC } 29212\end{array}$ & $\begin{array}{l}\text { S. Typhimurium } \\
\text { ATCC } 14028\end{array}$ & $\begin{array}{l}\text { C. albicans } \\
\text { ATCC } 10231\end{array}$ & TDCA & GDCA & Raffinose* $^{*}$ \\
\hline L. paracasei 62LP39 & 7.5 & 9 & 6.5 & 1.5 & $>10$ & 2 & + & + & + \\
\hline L. paracasei $8 / 18710$ & 5 & 9 & 7.5 & 2 & $>10$ & 1.5 & - & - & - \\
\hline L. paracasei $1 \mathrm{~A} 6 \mathrm{M}$ & 6 & 7.5 & 6 & 2 & $>10$ & 1 & + & + & + \\
\hline L. paracasei $3 \mathrm{AlM}$ & 3 & 6 & 5 & 1 & 7.5 & 0 & - & - & - \\
\hline L. paracasei 5/22019 & 6.5 & 8.5 & 5 & 0.5 & 7.5 & 0 & - & + & - \\
\hline L. paracasei $2 \mathrm{C} 6 \mathrm{M}$ & 6 & 5 & 6 & 0.5 & 7.5 & 0 & - & - & - \\
\hline L. paracasei 60LP37 & 7.5 & 9 & 9 & 1 & $>10$ & 0.5 & - & - & - \\
\hline L. paracasei 2A11 & 6.5 & 9 & 5 & 0.5 & $>10$ & 0 & - & - & - \\
\hline L. paracasei 6B1M & 5 & 7.5 & 6 & 1 & $>10$ & 0.5 & - & - & - \\
\hline L. paracasei 2B1M & 5 & 9 & 6 & 1.5 & $>10$ & 1 & - & - & - \\
\hline L. plantarum 11/20966 & 7 & 9 & 7.5 & 1 & $>10$ & 2.5 & + & + & + \\
\hline L. plantarum 19/20711 & 7.5 & 9 & 7.5 & 2 & $>10$ & 2 & + & + & + \\
\hline L. plantarum 4/16868 & 10 & 10 & 9 & 2.5 & $>10$ & 2 & + & + & + \\
\hline L. plantarum 8C1M & 5 & 5 & 6 & 1.5 & $>10$ & 0 & - & + & - \\
\hline L. plantarum 9FS15 & 6 & 1.5 & 5 & 1.5 & $>10$ & 1.5 & - & - & - \\
\hline L. plantarum $28 \mathrm{SP} 1$ & 4.5 & 2.5 & 3 & 1 & $>10$ & 1.5 & - & - & - \\
\hline L. plantarum 2AFS11 & 6.5 & 9 & 5 & 1 & $>10$ & 0.5 & - & - & - \\
\hline L. plantarum 5FS12 & 6 & 5 & 6 & 0.5 & 7.5 & 0 & - & - & - \\
\hline L. plantarum 12LP13 & 5 & 7.5 & 6 & 1 & $>10$ & 0 & - & - & - \\
\hline L. brevis $1 \mathrm{C} 3 \mathrm{M}$ & 6.5 & 7.5 & 6 & 0.5 & $>10$ & 4 & - & + & - \\
\hline L. brevis $9 / 11 \mathrm{~B}$ & 5 & 9 & 5 & 0.5 & $>10$ & 0.5 & - & + & - \\
\hline L. brevis $21 \mathrm{FS} 1 \mathrm{~B}$ & 5 & 7 & 5 & 1 & $>10$ & 0.5 & - & - & - \\
\hline L. brevis $9 \mathrm{~A} 3 \mathrm{M}$ & 4 & 5 & 5 & 0 & $>10$ & 0.5 & - & - & - \\
\hline
\end{tabular}

* Determined by API-50 CHL galleries (bioMérieux).

the resistance to bile salts toxicity is not related to hydrolase activity [21, 24-26]. Other mechanisms, alternative to $\mathrm{BSH}$, could be involved in counteract bile damage, as suggested by Noriega et al. [27].

BSH activity is frequently observed in specific groups of bacteria like Lactobacillus, Bifidobacterium, and Enterococcus isolated from the gastrointestinal tract (GIT): it has been reported for L. plantarum $[14,28]$ but not for $L$. paracasei strains $[26,29]$. Presently its role is controversial since it has been reported to act either positively in lowering of serum cholesterol [30] or negatively in increasing the level of undesirable deconjugated bile salts [31]. However, the bacterial genera most frequently used as probiotics (Bifidobacteria and Lactobacilli) are not capable of dehydroxylating deconjugated bile salts $[32,33]$ and so the majority of the breakdown products may be precipitated and excreted with feces [34]. On the other hand, BSH activity by a probiotic bacterium may be desirable since it increases the intestinal survival and persistence of producing strains, which in turn increases the overall beneficial effects associated with the strain [35].

Among the $\mathrm{BSH}$ positive strains, five showing the ability to ferment the trisaccharide raffinose, known for its prebiotic activity, and one with a high antagonistic activity against
C. albicans ATCC 10231 were selected for further functional characterization including in vitro tests to assess their survival under gastrointestinal environmental conditions and adhesion to gut epithelial tissue and to determine the enzymatic activity and some safety properties.

The survival responses of the strains, after 90 and $180 \mathrm{~min}$ of exposure to different gastrointestinal conditions, are shown in Table 2. The probiotic strain L. rhamnosus GG was included in the study for comparison purpose. All strains retained high viability during simulated gastric juice $(\mathrm{pH} 3.0)$ transit for $90 \mathrm{~min}$, and no significant reduction $(P>0.05)$ was found for any of the strains after exposure to artificial duodenum juice ( $\mathrm{pH} \mathrm{8.0)}$. The strains L. paracasei 62LP39 and L. plantarum 11/20966 and 4/16868 presented the best survival rates values with more than $98 \%$ surviving cells.

Exposure to gastric and intestinal fluids is the main environmental stress that decreases viability of ingested probiotics [36]. All selected strains maintained elevated cell numbers under conditions simulating passage through the human gastrointestinal tract, well comparable to the values obtained for the probiotic strain L. rhamnosus GG. The survival rates were above $90 \%$ after $3 \mathrm{~h}$ despite the high bile concentration (more than 1\%) used in the test. These results are consistent 
TABLE 2: Resistance of Lactobacillus strains to simulated stomach duodenum-passage (SSDP). The values are reported as log cfu/mL (mean \pm E.S.).

\begin{tabular}{|c|c|c|c|}
\hline Species & Initial mean count & $\begin{array}{c}\text { Survival after } \\
90 \text { min at } \mathrm{pH} 3.0\end{array}$ & $\begin{array}{c}\text { Survival after } 180 \text { min of } \\
\text { which } 90 \text { min in } 5 \% \text { oxgall }\end{array}$ \\
\hline \multicolumn{4}{|l|}{ Strain } \\
\hline \multicolumn{4}{|l|}{ L. paracasei } \\
\hline 62LP39 & $8.33 \pm 0.03$ & $8.67 \pm 0.11$ & $8.66 \pm 0.84$ \\
\hline $1 \mathrm{~A} 6 \mathrm{M}$ & $8.49 \pm 0.07$ & $8.08 \pm 0.02$ & $7.47 \pm 1.39$ \\
\hline \multicolumn{4}{|l|}{ L. plantarum } \\
\hline $11 / 20966$ & $8.66 \pm 0.15$ & $9.70 \pm 0.91$ & $8.62 \pm 0.17$ \\
\hline 19/207111 & $8.58 \pm 0.13$ & $8.58 \pm 0.3$ & $7.76 \pm 0.35$ \\
\hline $4 / 16868$ & $8.21 \pm 0.03$ & $8.06 \pm 0.2$ & $8.47 \pm 0.2$ \\
\hline \multicolumn{4}{|l|}{ L. brevis } \\
\hline $1 \mathrm{C} 3 \mathrm{M}$ & $8.59 \pm 0.23$ & $8.75 \pm 0.05$ & $8.39 \pm 0.14$ \\
\hline L. rhamnosus GG & $8.59 \pm 0.02$ & $9.03 \pm 0.18$ & $8.23 \pm 0.59$ \\
\hline
\end{tabular}

with those previously reported for other potentially probiotic strains belonging to L. paracasei [26] and L. plantarum [21] and correlate well with those obtained for BSH activity.

The adhesion ability of Lactobacillus strains is reported in Figure 1. All strains were able to adhere to Caco-2 cells to various extents (ranging from 3 to 20\%), confirming that adhesion is a strain-specific property. Three strains showed significantly higher adherence to Caco-2 cells than L. rhamnosus GG $(P<0.05)$. L. paracasei 62 LP39 was the most adhesive strain since approximately $20 \%$ of the added bacteria were bound to Caco-2 cells, followed by L. brevis 1 C3 M (14\%) and L. plantarum 11/20966 (10.5\%). A lower adhesion rate was observed for the strain L. paracasei $1 \mathrm{~A} 6 \mathrm{M}$ (3\%). The percentage of adhesion of L. rhamnosus GG, used as positive control, was similar to those obtained with the same strain in other studies $[37,38]$ but lower than the values found by $\mathrm{Xu}$ et al. [39]. L. plantarum strains have been shown to adhere more efficiently to Caco-2 cells than $L$. paracasei or $L$. brevis [29, 38], although Toumola and Salminen [37] obtained an adhesion percentage at the level of $6.7 \%$. Other authors observed that $L$. paracasei strains were effective in reducing adhesion of Salmonella to Caco-2 cells in competitive assays, in spite of their low adherence ability [40-42].

Several in vitro studies suggested that probiotic adhesion may interfere with the adherence of pathogens, exerting a barrier against pathogen colonization through competitive exclusion mechanisms $[39,40]$.

Enzymatic characterization of the selected strains was carried out in order to evaluate their potential for using as adjunct cultures in the manufacturing of probiotic cheese and is reported in Table 3. All strains exhibited high aminopeptidase activity (leucine and valine arylamidase) while esterase and lipase activities were generally moderate to low. The proteolytic and $\mathrm{N}$-acetyl- $\beta$-glucosaminidase activities were absent or very low. All strains exhibited strong $\beta$ galactosidase and moderate-to-high $\alpha$-galactosidase activities, which are responsible for the hydrolysis of lactose and raffinose, respectively. None of the strains showed $\beta$ glucuronidase or $\alpha$-mannosidase activity.

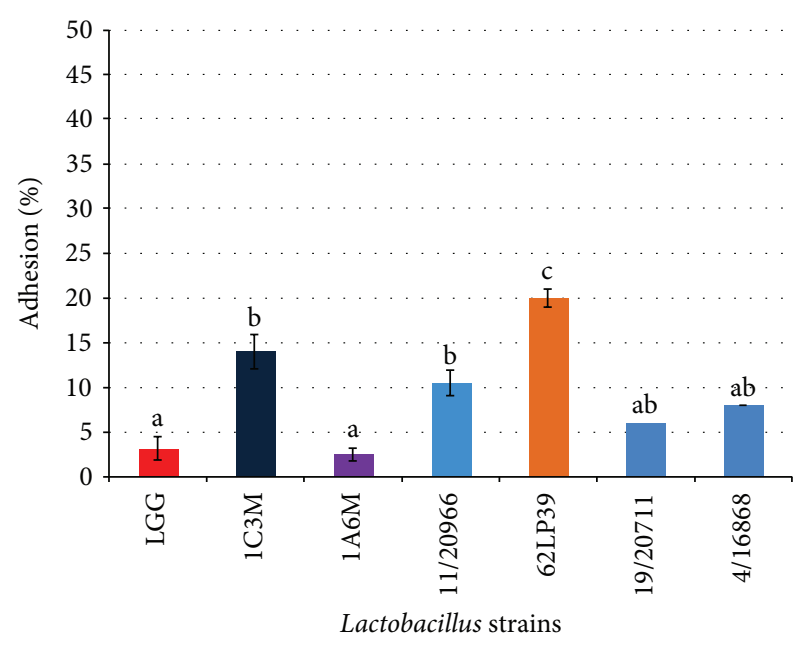

Figure 1: Adhesion ability to Caco-2 human colon cell lines of dairy Lactobacillus strain (mean \pm E.S. of three independent experiments). Mean values with different superscript letters were significantly different at $P<0.05$.

Overall, the enzymatic profiles of our strains are similar to those reported by other authors particularly for the species L. plantarum [42-44]. Mathara et al. [43] could not detect any $\beta$-galactosidase in $14 \mathrm{~L}$. paracasei isolates and Herreros et al. [42] found a certain degree of activity in two strains of $L$. brevis. Strains with low proteinase, high peptidase, and low esterase-lipase activities may be useful in reducing bitterness and improving body and texture defects $[43,44]$. $\beta$ galactosidase activity is an important feature for strains to be used as probiotics, since it may be useful in improving lactose tolerance in the gut [45]. The lack of $\beta$-glucuronidase activity is an important trait, as well, since its negative role has been suggested in increasing the risk of carcinogenesis [46].

In order for a strain to be used as probiotic culture, it should be evaluated for the presence of virulence determinants to determine what potential risks might be involved in its use. Biogenic amines are produced by LAB during the 
TABLE 3: Enzymatic profiles of selected dairy Lactobacillus strains assayed by the API-ZYM system.

\begin{tabular}{|c|c|c|c|c|c|c|}
\hline \multirow{3}{*}{ Enzyme tested } & \multicolumn{6}{|c|}{ Strains } \\
\hline & \multicolumn{2}{|c|}{ L. paracasei } & \multicolumn{3}{|c|}{ L. plantarum } & \multirow{2}{*}{$\begin{array}{c}\text { L. brevis } \\
1 \mathrm{C} 3 \mathrm{M}\end{array}$} \\
\hline & 62LP39 & $1 \mathrm{~A} 6 \mathrm{M}$ & $11 / 20966$ & $19 / 20711$ & $4 / 116868$ & \\
\hline Alkaline phosphatase & 20 & 10 & 10 & 5 & 10 & 5 \\
\hline Esterase $(\mathrm{C} 4)$ & 10 & 5 & 5 & 0 & 5 & 20 \\
\hline Esterase lipase (C8) & 10 & 10 & 5 & 10 & 10 & 10 \\
\hline Lipase (C14) & 10 & 20 & 10 & 10 & 20 & 20 \\
\hline Leucine arylamidase & $>40$ & $>40$ & $>40$ & 30 & $>40$ & $>40$ \\
\hline Valine arylamidase & $>40$ & $>40$ & 30 & 10 & 30 & $>40$ \\
\hline Cystine arylamidase & 20 & 20 & 10 & 0 & 20 & 20 \\
\hline Trypsin & 5 & 5 & 0 & 0 & 5 & 0 \\
\hline$\alpha$-Chymotrypsin & 0 & 0 & 5 & 5 & 5 & 5 \\
\hline Acid phosphatase & 20 & 30 & 20 & 20 & 20 & 30 \\
\hline Napthol-AS-BI-phosphohydrolase & 30 & 20 & 10 & 10 & 10 & 10 \\
\hline$\alpha$-Galactosidase & 20 & 10 & 10 & 0 & 0 & 30 \\
\hline$\beta$-Galactosidase & $>40$ & 30 & $>40$ & 10 & 20 & $>40$ \\
\hline$\beta$-Glucuronidase & 0 & 0 & 0 & 0 & 0 & 0 \\
\hline$\alpha$-Glucosidase & 30 & 30 & 20 & 0 & 20 & 30 \\
\hline$\beta$-Glucosidase & 30 & 10 & 30 & 20 & 30 & 30 \\
\hline N-Acetyl-glucosaminidase & 5 & 0 & 0 & 5 & 0 & 0 \\
\hline$\alpha$-Mannosidase & 0 & 0 & 0 & 0 & 0 & 0 \\
\hline$\alpha$-Fucosidase & 0 & 5 & 0 & 0 & 0 & 0 \\
\hline
\end{tabular}

Enzyme activity is expressed as the approximate nanomoles of hydrolysed substrate after $4 \mathrm{~h}$ of incubation at $37^{\circ} \mathrm{C}$.

TABLE 4: Antibiotic susceptibility of selected Lactobacillus strains.

\begin{tabular}{|c|c|c|c|c|c|c|c|c|c|c|c|c|c|}
\hline \multirow{2}{*}{ Species } & \multirow{2}{*}{ Strain } & \multicolumn{12}{|c|}{ Antibiotic tested ${ }^{*}$} \\
\hline & & AM10 & AmC30 & VA30 & TEC30 & TE30 & S10 & K30 & GM10 & $\mathrm{C} 30$ & E15 & CIP30 & RA30 \\
\hline \multirow{2}{*}{ L. paracasei } & 62LP39 & $\mathrm{S}$ & $\mathrm{S}$ & $\mathrm{R}$ & $\mathrm{R}$ & $\mathrm{S}$ & $\mathrm{R}$ & $\mathrm{R}$ & MS & $S$ & $S$ & $\mathrm{R}$ & $\mathrm{S}$ \\
\hline & $1 \mathrm{~A} 6 \mathrm{M}$ & $S$ & S & $\mathrm{R}$ & $\mathrm{R}$ & S & $\mathrm{R}$ & $\mathrm{R}$ & MS & $S$ & $S$ & $\mathrm{R}$ & S \\
\hline \multirow{3}{*}{ L. plantarum } & $11 / 20966$ & S & S & $\mathrm{R}$ & $\mathrm{R}$ & $S$ & $\mathrm{R}$ & $\mathrm{R}$ & MS & $S$ & $S$ & $\mathrm{R}$ & S \\
\hline & $19 / 20711$ & $S$ & S & $\mathrm{R}$ & $\mathrm{R}$ & S & $\mathrm{R}$ & $\mathrm{R}$ & MS & S & S & $\mathrm{R}$ & S \\
\hline & $4 / 16868$ & $S$ & $S$ & $\mathrm{R}$ & $\mathrm{R}$ & $S$ & $\mathrm{R}$ & $\mathrm{R}$ & MS & $S$ & $S$ & $\mathrm{R}$ & $S$ \\
\hline L. brevis & $1 \mathrm{C} 3 \mathrm{M}$ & $S$ & $S$ & $\mathrm{R}$ & $\mathrm{R}$ & $S$ & $\mathrm{R}$ & $\mathrm{R}$ & MS & $S$ & $S$ & $\mathrm{R}$ & $S$ \\
\hline
\end{tabular}

${ }^{*}$ Antibiotics: (AM) ampicillin; (AmC) amoxicillin/clavulanic acid; (VA) vancomycin; (TEC) teicoplanin; (TE) tetracycline; (S) streptomycin; (K) kanamycin; (GM) gentamicin; (C) chloramphenicol; (E) erythromycin; (Cip) ciprofloxacin; (RA) rifampicin. R: resistant; S: sensitive; MS: moderately susceptible.

process of fermentation of foods and beverages by amino acid decarboxylation. Bover-Cid and Holzapfel [16] suggested that the capability to produce biogenic amines in a synthetic medium might be strain dependent rather than being related to specific species. In our screening, none of the strains tested was found to decarboxylate lysine, histidine, ornithine, or tyrosine (data not shown), in agreement with other findings $[29,47]$.

The Lactobacillus strains were assayed for their resistance to 12 antibiotics using a disc diffusion method on MRS agar plates under anaerobic conditions, and the results are reported in Table 4. Within the group of antimicrobial agents that inhibit the cell wall synthesis, all strains were resistant to vancomycin and teicoplanin and susceptible to ampicillin and amoxicillin/clavulanic acid. All strains were susceptible to tetracycline, chloramphenicol, and erythromycin, moderately susceptible to gentamycin, and resistant to streptomycin and kanamycin. As for the antibiotics that inhibit the nucleic acids synthesis, all strains were resistant to ciprofloxacin and susceptible to rifampicin.

Our results are in substantial agreement with those reported for L. plantarum and L. paracasei strains [26, 29], although other authors observed a certain variability in strains' reaction to tetracycline $[19,48]$.

The resistance observed against some antibiotics tested suggests that our strains would not be affected by therapies using these antibiotics and might help maintain the natural balance of intestinal microflora during antibiotic treatments [49]. Resistance to some antibiotics such as aminoglycosides, quinolones, and glycopeptides appears to be intrinsic for Lactobacilli $[50,51]$. In particular, vancomycin resistance is well documented in Lactobacilli and it has been attributed to 
the synthesis of modified cell wall peptidoglycan precursors that end in a depsipeptide d-alanine-d-lactate instead of the dipeptide $\mathrm{d}$-alanine-d-alanine, the target for vancomycin activity [52]. Moreover, Klein et al. [50] showed that the glycopeptide resistance in Lactobacillus strains is not of the transmissible type. The strains tested in our work do not seem to represent a source for transfer of genes encoding resistance, since they were phenotypically susceptible to tetracycline, erythromycin, and chloramphenicol, but the absence of the genes needs to be confirmed genotypically. Comunian et al. [48] recently found that tetracycline and erythromycin resistance is not usually detected in strains originating from cheeses produced in geographical areas (such as Sardinia island) where no systematic use of antibiotics as growth promoters was carried out over the years in animal husbandry.

Finally, none of the strains was found to be haemolytic (data not shown), in agreement with previous studies [53].

\section{Conclusions}

In conclusion, our results indicate that some Lactobacillus strains (particularly L. paracasei 62LP39, L. plantarum $11 / 20966$ and $4 / 16868$, and L. brevis $1 C 3$ M) could be considered appropriate probiotic candidates, due to resistance to GIT simulated conditions, antimicrobial properties, adhesion to human intestinal epithelial cell-line (Caco-2), and absence of undesirable properties. They could be used as adjunct cultures for contributing to the quality and health related functional properties of dairy products; however, additional studies are required to confirm in vivo this findings as well as to assess the strains stability to manufacturing processes.

\section{Conflict of Interests}

The authors declare that there is no conflict of interests regarding the publication of this paper.

\section{Acknowledgments}

This work has been supported by Regione Autonoma Sardegna (RAS, L.R. 7/2007, CRP 17617). Silvia Viale was supported by a Grant from P.O. Sardegna FSE 2007-2013.

\section{References}

[1] S. Rodgers, "Novel applications of live bacteria in food services: probiotics and protective cultures," Trends in Food Science and Technology, vol. 19, no. 4, pp. 188-197, 2008.

[2] FAO/WHO, Probiotics in Food: Health and Nutritional Properties and Guidelines for Evaluation, FAO Food and Nutrition Paper no. 85, FAO/WHO, Rome, Italy, 2006.

[3] R. Karimi, A. M. Mortazavian, and A. G. Da Cruz, "Viability of probiotic microorganisms in cheese during production and storage: a review," Dairy Science and Technology, vol. 91, no. 3, pp. 283-308, 2011.

[4] S. Menéndez, J. A. Centeno, R. Godínez, and J. L. RodríguezOtero, "Effects of Lactobacillus strains on the ripening and organoleptic characteristics of Arzúa-Ulloa cheese," Intenational Journal of Food Microbiology, vol. 59, pp. 37-46, 2000.
[5] D. Jonkers, J. Penders, A. Masclee, and M. Pierik, "Probiotics in the management of inflammatory bowel disease: a systematic review of intervention studies in adult patients," Drugs, vol. 72, no. 6, pp. 803-823, 2012.

[6] F. Leroy and L. de Vuyst, "Lactic acid bacteria as functional starter cultures for the food fermentation industry," Trends in Food Science and Technology, vol. 15, no. 2, pp. 67-78, 2004.

[7] European Food Safety Authority, "QPS: qualified presumption of safety of microorganisms in food and feed," EFSA Scientific Colloquium Summary Report, European Food Safety Authority, Brussels, Belgium, 2004.

[8] European Food Safety Authority, "Scientific opinion on the maintenance of the list of QPS biological agents intentionally added to food and feed (2013 update)," The EFSA Journal, vol. 11, no. 11, pp. 1-108, 2013.

[9] L. Settanni and G. Moschetti, "Non-starter lactic acid bacteria used to improve cheese quality and provide health benefits," Food Microbiology, vol. 27, no. 6, pp. 691-697, 2010.

[10] M. B. Ugarte, D. Guglielmotti, G. Giraffa, J. Reinheimer, and E. Hynes, "Nonstarter lactobacilli isolated from soft and semihard Argentinean cheeses: genetic characterization and resistance to biological barriers," Journal of Food Protection, vol. 69, no. 12, pp. 2983-2991, 2006.

[11] M. B. Pisano, M. E. Fadda, M. Deplano, A. Corda, and S. Cosentino, "Microbiological and chemical characterization of Fiore Sardo, a traditional Sardinian cheese made from ewe's milk," International Journal of Dairy Technology, vol. 59, no. 3, pp. 171179, 2006.

[12] U. Schillinger and F. K. Lücke, "Antibacterial activity of Lactobacillus sake isolated from meat," Applied and Environmental Microbiology, vol. 55, no. 8, pp. 1901-1906, 1989.

[13] M. P. Dashkevicz and S. D. Feighner, "Development of a differential medium for bile salt hydrolase-active Lactobacillus spp.", Applied and Environmental Microbiology, vol. 55, no. 1, pp.11-16, 1989.

[14] M. G. Vizoso Pinto, C. M. A. P. Franz, U. Schillinger, and W. H. Holzapfel, "Lactobacillus spp. with in vitro probiotic properties from human faeces and traditional fermented products," International Journal of Food Microbiology, vol. 109, no. 3, pp. 205-214, 2006.

[15] M. F. Fernández, S. Boris, and C. Barbés, "Probiotic properties of human lactobacilli strains to be used in the gastrointestinal tract," Journal of Applied Microbiology, vol. 94, no. 3, pp. 449455, 2003.

[16] S. Bover-Cid and W. H. Holzapfel, "Improved screening procedure for biogenic amine production by lactic acid bacteria," International Journal of Food Microbiology, vol. 53, no. 1, pp. 3341, 1999.

[17] Clinical and Laboratory Standard Institute, Performance Standards for Antimicrobial Disk Susceptibility Tests; Approved Standard, Clinical and Laboratory Standard Institute, Wayne, Pa, USA, 10th edition, 2009.

[18] Clinical and Laboratory Standard Institute, Performance Standards for Antimicrobial Disk Susceptibility Tests; Twentieth Informational Supplement, (CLSI Document M100-S20), Clinical and Laboratory Standard Institute, Wayne, Pa, USA, 2010.

[19] R. N. Georgieva, I. N. Iliev, V. A. Chipeva, S. P. Dimitonova, J. Samelis, and S. T. Danova, "Identification and in vitro characterisation of Lactobacillus plantarum strains from artisanal Bulgarian white brined cheeses," Journal of Basic Microbiology, vol. 48, no. 4, pp. 234-244, 2008. 
[20] F. Bendali, A. Durand, M. Hébraud, and D. Sadoun, "Lactobacillus paracasei subsp. paracasei: an Algerian isolate with antibacterial activity against enteric pathogens and probiotic fitness," Journal of Food and Nutrition Research, vol. 50, no. 3, pp. 139-149, 2011.

[21] M. Zago, M. E. Fornasari, D. Carminati et al., "Characterization and probiotic potential of Lactobacillus plantarum strains isolated from cheeses," Food Microbiology, vol. 28, no. 5, pp. 10331040, 2011.

[22] A. L. Servin, "Antagonistic activities of lactobacilli and bifidobacteria against microbial pathogens," FEMS Microbiology Reviews, vol. 28, no. 4, pp. 405-440, 2004.

[23] I. de Smet, L. van Hoorde, M. vande Woestyne, H. Christiaens, and W. Verstraete, "Significance of bile salt hydrolytic activities of lactobacilli," Journal of Applied Bacteriology, vol. 79, no. 3, pp. 292-301, 1995.

[24] S. A. Moser and D. C. Savage, "Bile salt hydrolase activity and resistance to toxicity of conjugated bile salts are unrelated properties in lactobacilli," Applied and Environmental Microbiology, vol. 67, no. 8, pp. 3476-3480, 2001.

[25] E. Bertazzoni Minelli, A. Benini, M. Marzotto et al., "Assessment of novel probiotic Lactobacillus casei strains for the production of functional dairy foods," International Dairy Journal, vol. 14, no. 8, pp. 723-736, 2004.

[26] L. Solieri, A. Bianchi, G. Mottolese, F. Lemmetti, and P. Giudici, "Tailoring the probiotic potential of non-starter Lactobacillus strains from ripened Parmigiano Reggiano cheese by in vitro screening and principal component analysis," Food Microbiology, vol. 38, pp. 240-249, 2014.

[27] L. Noriega, I. Cuevas, A. Margolles, and C. G. de los ReyesGavilán, "Deconjugation and bile salts hydrolase activity by Bifidobacterium strains with acquired resistance to bile," International Dairy Journal, vol. 16, no. 8, pp. 850-855, 2006.

[28] A. Belicova, M. Mikulasova, and R. Dusinsky, "Probiotic potential and safety properties of Lactobacillus plantarum from Slovak Bryndza cheese," BioMed Research International, vol. 2013, Article ID 760298, 8 pages, 2013.

[29] L. Lavilla-Lerma, R. Pérez-Pulido, M. Martínez-Bueno, M. Maqueda, and E. Valdivia, "Characterization of functional, safety, and gut survival related characteristics of Lactobacillus strains isolated from farmhouse goat's milk cheeses," International Journal of Food Microbiology, vol. 163, no. 2-3, pp. 136-145, 2013.

[30] T. D. T. Nguyen, J. H. Kang, and M. S. Lee, "Characterization of Lactobacillus plantarum $\mathrm{PH} 04$, a potential probiotic bacterium with cholesterol-lowering effects," International Journal of Food Microbiology, vol. 113, no. 3, pp. 358-361, 2007.

[31] G. Corzo and S. E. Gilliland, "Bile salt hydrolase activity of three strains of Lactobacillus acidophilus," Journal of Dairy Science, vol. 82, no. 3, pp. 472-480, 1999.

[32] T. Takahashi and M. Morotomi, "Absence of cholic acid $7 \alpha-$ dehydroxylase activity in the strains of Lactobacillus and Bifdobacterium," Journal of Dairy Science, vol. 77, no. 11, pp. 32753286, 1994.

[33] Y. T. Ahn, G. B. Kim, K. S. Lim, Y. J. Baek, and H. U. Kim, "Deconjugation of bile salts by Lactobacillus acidophilus isolates," International Dairy Journal, vol. 13, no. 4, pp. 303-311, 2003.

[34] L. A. Thomas, M. J. Veysey, T. Bathgate et al., "Mechanism for the transit-induced increase in colonic deoxycholic acid formation in cholesterol cholelithiasis," Gastroenterology, vol. 119, no. 3, pp. 806-815, 2000.
[35] M. Begley, C. Hill, and C. G. M. Gahan, "Bile salt hydrolase activity in probiotics," Applied and Environmental Microbiology, vol. 72, no. 3, pp. 1729-1738, 2006.

[36] U. Schillinger, C. Guigas, and W. H. Holzapfel, "In vitro adherence and other properties of lactobacilli used in probiotic yoghurt-like products," International Dairy Journal, vol. 15, no. 12, pp. 1289-1297, 2005.

[37] E. M. Tuomola and S. J. Salminen, "Adhesion of some probiotic and dairy Lactobacillus strains to Caco-2 cell cultures," International Journal of Food Microbiology, vol. 41, no. 1, pp. 45-51, 1998.

[38] C. L. Ramos, L. Thorsen, R. F. Schwan, and L. Jespersen, "Strain-specific probiotics properties of Lactobacillus fermentum, Lactobacillus plantarum and Lactobacillus brevis isolates from Brazilian food products," Food Microbiology, vol. 36, no. 1, pp. 22-29, 2013.

[39] H. Xu, H. S. Jeong, H. Y. Lee, and J. Ahn, "Assessment of cell surface properties and adhesion potential of selected probiotic strains," Letters in Applied Microbiology, vol. 49, no. 4, pp. 434442, 2009.

[40] E. Grzesiuk, A. Jankowska, D. Laubitz, H. Antushevich, and R. Zabielski, "Competition of Lactobacillus paracasei with Salmonella enterica for adhesion to Caco-2 cells," Journal of Biomedicine and Biotechnology, vol. 2008, Article ID 357964, 6 pages, 2008.

[41] S. M. Lim and D. H. Ahn, "Factors affecting adhesion of lactic acid bacteria to Caco-2 cells and inhibitory effect on infection of Salmonella Typhimurium," Journal of Microbiology and Biotechnology, vol. 22, no. 12, pp. 1731-1739, 2012.

[42] M. A. Herreros, J. M. Fresno, M. J. González Prieto, and M. E. Tornadijo, "Technological characterization of lactic acid bacteria isolated from Armada cheese (a Spanish goats' milk cheese)," International Dairy Journal, vol. 13, no. 6, pp. 469-479, 2003.

[43] J. M. Mathara, U. Schillinger, P. M. Kutima, S. K. Mbugua, and W. H. Holzapfel, "Isolation, identification and characterisation of the dominant microorganisms of kule naoto: the Maasai traditional fermented milk in Kenya," International Journal of Food Microbiology, vol. 94, no. 3, pp. 269-278, 2004.

[44] R. Georgieva, I. Iliev, T. Haertlé, J. Chobert, I. Ivanova, and S. Danova, "Technological properties of candidate probiotic Lactobacillus plantarum strains," International Dairy Journal, vol. 19, no. 11, pp. 696-702, 2009.

[45] M. de Vrese, A. Stegelmann, B. Richter, S. Fenselau, C. Laue, and J. Schrezenmeir, "Probiotics-compensation for lactase insufficiency," The American Journal of Clinical Nutrition, vol. 73, no. 2, pp. 421s-429s, 2001.

[46] P. M. Heavey and I. R. Rowland, "Microbial-gut interaction in health and disease. Gastrointestinal cancer," Best Practice \& Research: Clinical Gastroenterology, vol. 18, no. 2, pp. 323-336, 2004.

[47] Y. Ji, H. Kim, H. Park et al., "Functionality and safety of lactic bacterial strains from Korean kimchi," Food Control, vol. 31, no. 2, pp. 467-473, 2013.

[48] R. Comunian, E. Daga, I. Dupré et al., "Susceptibility to tetracycline and erythromycin of Lactobacillus paracasei strains isolated from traditional Italian fermented foods," International Journal of Food Microbiology, vol. 138, no. 1-2, pp. 151-156, 2010.

[49] S. Salminen, A. Von Wright, L. Morelli et al., "Demonstration of safety of probiotics-a review," International Journal of Food Microbiology, vol. 44, no. 1-2, pp. 93-106, 1998.

[50] G. Klein, C. Hallmann, I. A. Casas, J. Abad, J. Louwers, and G. Reuter, "Exclusion of van $A, v a n B$ and vanC type glycopeptide 
resistance in strains of Lactobacillus reuteri and Lactobacillus rhamnosus used as probiotics by polymerase chain reaction and hybridization methods," Journal of Applied Microbiology, vol. 89, no. 5, pp. 815-824, 2000.

[51] M. Danielsen and A. Wind, "Susceptibility of Lactobacillus spp. to antimicrobial agents," International Journal of Food Microbiology, vol. 82, no. 1, pp. 1-11, 2003.

[52] S. Handwerger, M. J. Pucci, K. J. Volk, J. Liu, and M. S. Lee, "Vancomycin-resistant Leuconostoc mesenteroides and Lactobacillus casei synthesize cytoplasmic peptidoglycan precursors that terminate in lactate," Journal of Bacteriology, vol. 176, no. 1, pp. 260-264, 1994.

[53] G. Zoumpopoulou, B. Foligne, K. Christodoulou, C. Grangette, B. Pot, and E. Tsakalidou, "Lactobacillus fermentum ACADC 179 displays probiotic potential in vitro and protects against trinitrobenzene sulfonic acid (TNBS)-induced colitis and Salmonella infection in murine models," International Journal of Food Microbiology, vol. 121, no. 1, pp. 18-26, 2008. 

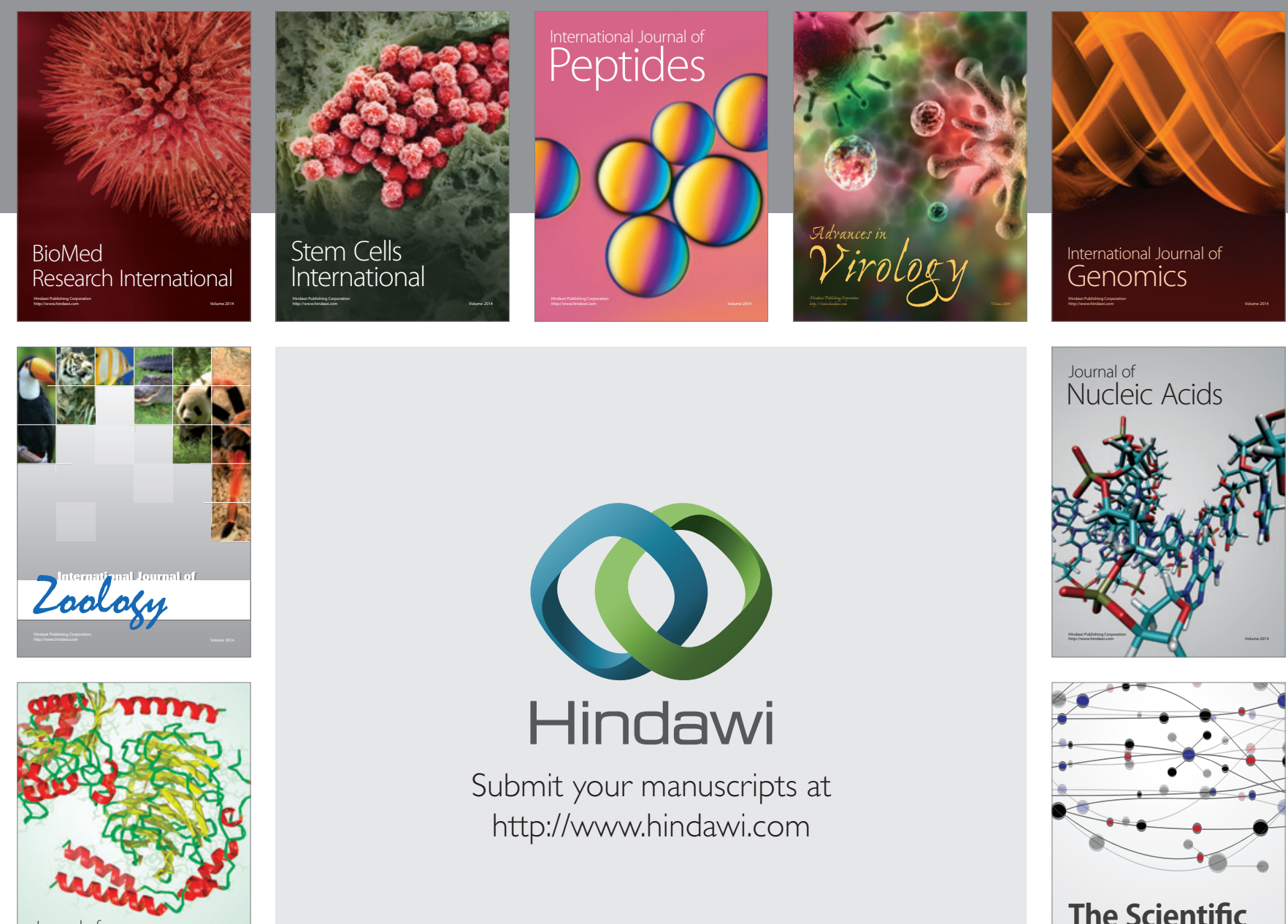

Submit your manuscripts at

http://www.hindawi.com

Journal of
Signal Transduction
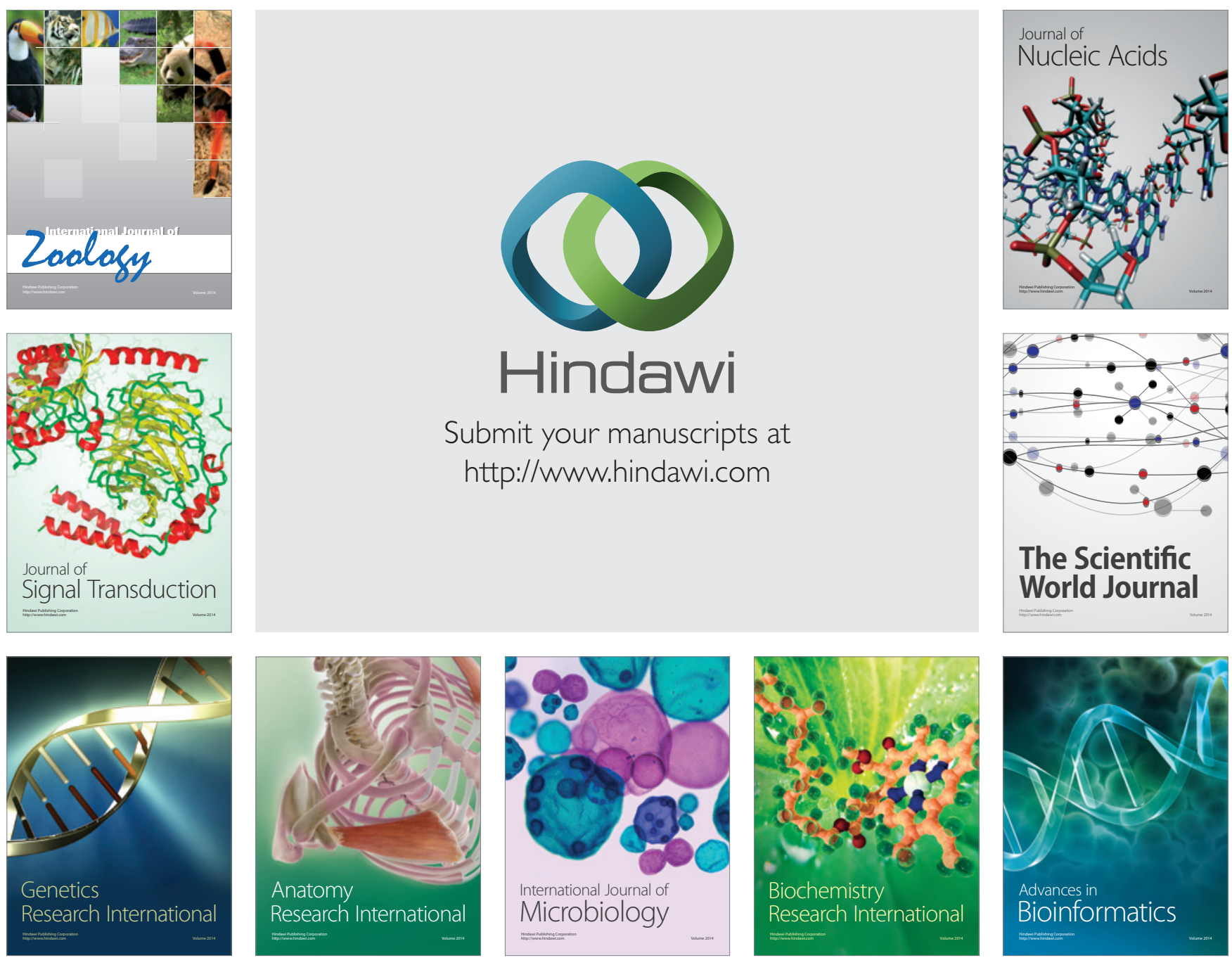

The Scientific World Journal
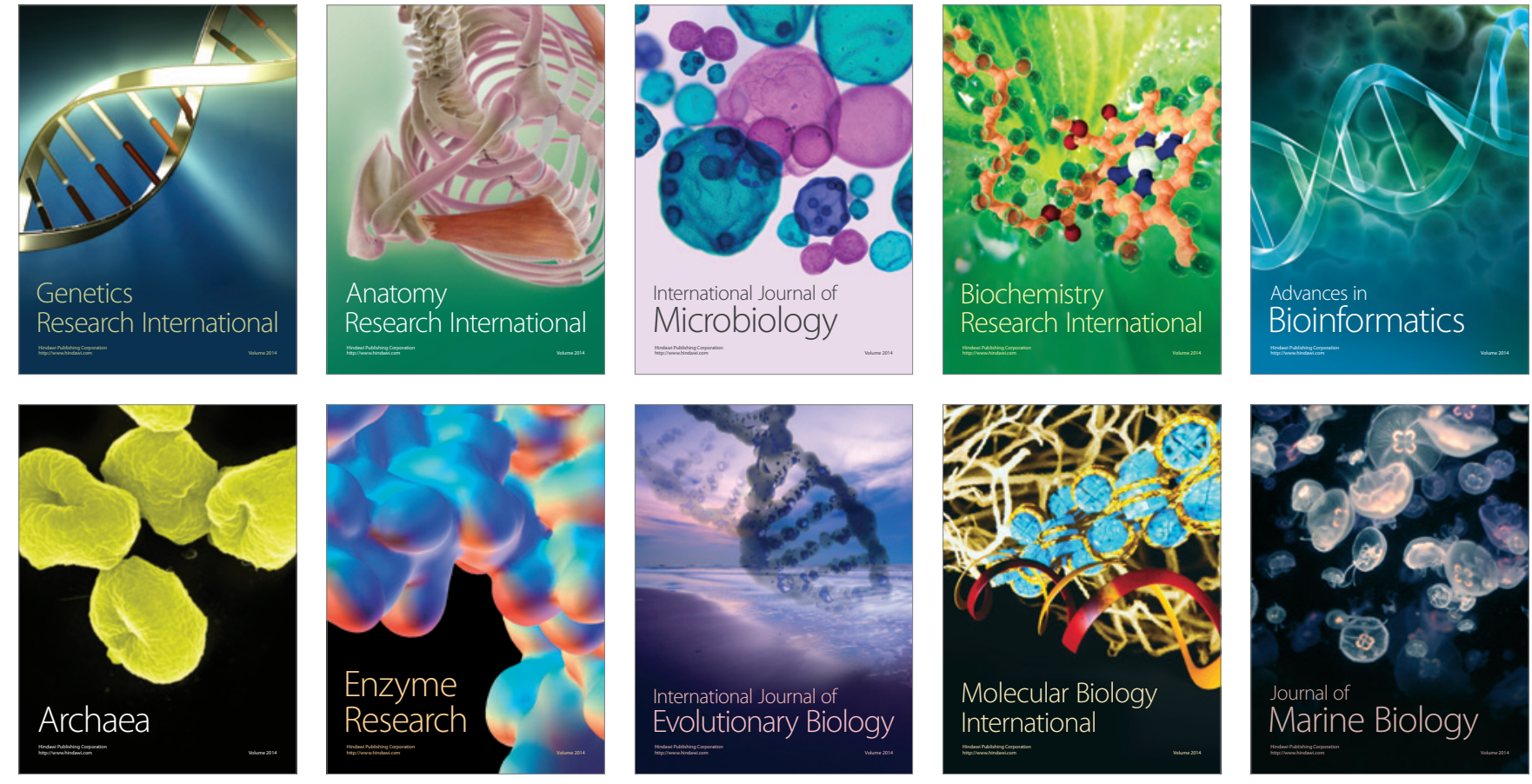